\title{
Numerical simulation of landslide over erodible surface
}

Wei Liu' ${ }^{1,2}$, Siming $\mathrm{He}^{1,2,3^{*}}$ and Xinpo $\mathrm{Li}^{1,2}$

\begin{abstract}
Background: Estimating the magnitude and intensity of landslides is a fundamental requirement in quantitatively evaluating the risks involved, and preparing a mitigation strategy. Though the physics-based dynamic model of landslide can predict the travel distance, kinematic velocity, and hazard zone, the effects of erosion and the excess pore water pressure during the dynamic process of landslide are often ignored.

Results: In order to study these factors, a physics-based dynamic model of landslide considering erosion and excess pore water pressure is presented in this paper. A high-precision numerical method based on the finite volume method is proposed to solve the model equations. Several numerical tests are performed to verify the numerical method and the model. The effects of erosion and excess pore water pressure on the dynamic process of landslide are also analyzed.

Conclusions: The numerical results indicate that the scale and mobility of a landslide are influenced by the effect of erosion and excess pore water pressure. The excess pore water pressure can reduce the resistance to shear stress from the erodible bed and lead to a higher erosion amount and longer moving distance of the landslide. It also affects the degree of erosion and further affects the dynamic process of the landslide. The sensitivity analysis of the parameters that influence excess pore water pressure indicate that these parameters have a significant impact on the evolution of excess pore water pressure, and that the degree of saturation of bed sediment has the highest influence on excess pore water pressure.
\end{abstract}

Keywords: Landslide; Erosion; Excess pore water pressure; Numerical simulation

\section{Background}

Landslides are a natural phenomenon that can strike human settlements in mountainous regions resulting in serious consequences, including untold number of deaths and injuries and massive economic losses (Wang and Sassa 2010; Luna and Remaitre 2012). Because of the huge destructive power of landslides, understanding how to prevent them is becoming more and more important for hazard evaluation, risk assessment, and the preparation of mitigation measures (Savage and Hutter 1989; Chen and Lee 2000; Iverson and Denlinger 2001; Hungr et al. 2005; Pudasaini and Hutter 2007). Predicting the

\footnotetext{
* Correspondence: hsm@imde.ac.cn

'Key laboratory of Mountain Hazards and Surface Process, Chinese Academy of Sciences, Chengdu 610041, China

${ }^{2}$ Institute of Mountain Hazards and Environment (IMHE), Chinese Academy of Sciences, Chengdu 610041, China

Full list of author information is available at the end of the article
}

maximum extension and velocity of landslide is one of the ultimate goals.

In recent years, several physics-based dynamic models for landslides have been developed based on the constitutive law of fluid mechanics (Pitman et al. 2003; McDougall and Hungr 2004, 2005; Goren and Aharonov 2007; Goren and Aharonov 2009; George and Iverson 2011; Luna and Remaitre 2012). Most of them assume a constant landslide volume for the duration of motion, neglecting the important role of entrainment found along the landslide path. However, landslide paths are typically covered by surficial deposits such as colluvium, residual soil, and organics (McDougall and Hungr 2005). These deposits may be loose and have high water content, and may be mobilized by the rapid loading of the moving landslide. The phenomena of entrainment is frequently observed on landslides in fields, and the deposited materials may accumulate several times in volume with respect to the initially mobilized mass (Vandine 
and Bovis 2002). Erosion action not only increases the volume of landslide, but also enhances the landslide mobility significantly, including the travel distance and area covered by the landslide hazard (Crosta et al. 2003; McDougall and Hungr 2005; Iverson 2012). Therefore, it is important for the landslide dynamic model to consider the entrainment effect. In addition, pore water pressure changes caused by the failure of path material can occur at the base of a rapid landslide. The pore water pressure also plays a crucial role in the dynamic process of landslide, because it counteracts the normal stresses at the grain contact, and thereby reduces inter-granular friction (George and Iverson 2011). Generally speaking, the pore water pressure includes a hydrostatic component that balances the pore-fluid weight, and a non-hydrostatic or "excess" component (Iverson 2009). The excess pore water pressure at the base of the landslide may be produced by grain-crushing (Gerolymos and Gazetas 2007), dilatancy (Savage and Iverson 2009), effective stress (Luna and Remaitre 2012), and thermal pressurization (Vardoulakis 2000; Goren and Aharonov 2007; De Blasio and Elverhøi 2008; Goren and Aharonov 2009).

In this study, considering the effects of entrainment and excess pore water pressure, a physics-based dynamic model for landslide is proposed in order to further study the dynamic mechanism of the landslide. For solving the model equations, a high-precision numerical method based on the finite volume method is also proposed. The paper is organized as follows: The twodimensional Savage-Hutter type model is presented in section 2 . The entrainment model and the excess pore water pressure model are introduced in section 3 and 4, respectively. The full model is covered in section 5 . The numerical method is presented in section 6 , and a series of numerical tests are performed in section 7 . Finally, section 8 summarizes the results with concluding remarks.

\section{Model equations}

\section{Two-dimensional Savage-Hutter type dynamic model}

In this section, a model taking into account the effects of entrainment and excess pore water pressure is presented to describe the dynamic mechanism of landslides. The depth-averaged theory based on the assumptions of constant porosity and equal velocity is applied to the model equations (Gray 1999; Iverson and Denlinger 2001; Pudasaini et al. 2003; Savage and Iverson 2003; Pitman and Le 2005). In the fixed Cartesian coordinate system $O-x y z$, where $z$ denotes the normal direction, the model equations can be written as,

$$
\frac{\partial h}{\partial t}+\frac{\partial h u}{\partial x}+\frac{\partial h v}{\partial y}=E
$$

$$
\begin{aligned}
& \frac{\partial h u}{\partial t}+\frac{\partial}{\partial x}\left(h u^{2}+\frac{1}{2} k_{a p} g_{z} h^{2}\right)+\frac{\partial(h u v)}{\partial y} \\
& =u\left(z_{b}\right) E+g_{x} h-\operatorname{sgn}\left(\frac{\partial u}{\partial y}\right) k_{a p} h \frac{\partial\left(g_{z} h\right)}{\partial y} \sin \phi_{\text {int }}-\frac{u}{\sqrt{u^{2}+v^{2}}} \frac{\tau_{b}}{\rho} \\
& \frac{\partial h v}{\partial t}+\frac{\partial(h u v)}{\partial x}+\frac{\partial}{\partial y}\left(h v^{2}+\frac{1}{2} k_{a p} g_{z} h^{2}\right) \\
& =v\left(z_{b}\right) E+g_{y} h-\operatorname{sgn}\left(\frac{\partial v}{\partial x}\right) k_{a p} h \frac{\partial\left(g_{z} h\right)}{\partial x} \sin \phi_{\text {int }}-\frac{v}{\sqrt{u^{2}+v^{2}}} \frac{\tau_{b}}{\rho}
\end{aligned}
$$

where $h$ is the landslide height; $u$ and $v$ are the velocities in the $x$ and $y$ directions, respectively; $g_{x}, g_{y}$, and $g_{z}$ are components of gravitational acceleration in the $x, y$, and $z$ directions, respectively; $E$ represents the erosion; $u\left(z_{b}\right)$ and $v\left(z_{b}\right)$ are the velocities at the bottom of the landslide in the $x$ and $y$ directions, respectively; $\phi_{\text {int }}$ is internal friction angle of the landslide; $\rho=(1-c) \rho_{f}+c \rho_{s}$ is the density of the landslide, in which $\rho_{f}$ is fluid density, $\rho_{s}$ is solid density, and $c$ is solid volume fraction; $\tau_{b}$ represents the basal shear stress of the landslide; $k_{a p}$ is the lateral pressure coefficient, and can be described as

$$
k_{a p}=2 \frac{1 \pm\left[1-\cos ^{2} \phi_{\text {int }}\left(1+\tan ^{2} \phi_{b e d}\right)\right]^{\frac{1}{2}}}{\cos ^{2} \phi_{\text {int }}}-1,
$$

where $\phi_{b e d}$ is the bed friction angle; "-" and "+" correspond to the active state $(\partial u / \partial x+\partial v / \partial y \geq 0)$ and passive state $(\partial u / \partial x+\partial v / \partial y \leq 0)$, respectively.

Eq. (1) represents the mass conservation for the landslide. Eqs. (2) and (3) represent the momentum conservation equation for unit volume of the landslide. The first and second terms on the right hand side of Eqs. (2) and (3) indicate the basal erosion effect and gravity force, respectively. The third term on the right hand side of Eqs. (2) and (3) represents the transverse shear stress. The fourth term on the right hand side of Eqs. (2) and (3) represents the frictional resistance in each direction.

\section{Entrainment model}

The entrainment model equation plays a significant role in properly assessing the total entrainment volume of a landslide. In the past few years, many entrainment model equations have been proposed, and they have greatly improved our understanding (Pitman et al. 2003; Cao et al. 2004; McDougall and Hungr 2005; Agliardi et al. 2009; Hutter and Luca 2012; Iverson 2012). Presently, there is an agreement among researchers that the pore pressure is an important factor that influences the entrainment dynamic process (Pitman and Le 2005; McDougall and Hungr 2005; Iverson 2012; Iverson and Ouyang 2014). It is shown that the formula for entrainment rate must satisfy the boundary momentum jump 
condition (Iverson and Ouyang 2014), and can be written as

$$
E=\frac{\tau_{b}-\tau_{s}}{\rho \sqrt{u^{2}+v^{2}}},
$$

where $\tau_{b}$ is total basal traction from the landslide flow; $\tau_{s}$ is the total resistance shear stress from the erodible surface; and the formula should also satisfy the Coulomb failure criterion. The quadratic velocity-dependent model proposed by Fraccarollo and Capart (2002) is applied to $\tau_{b}$, and is expressed as

$$
\tau_{\mathrm{b}}=C_{f} \rho_{s}\left(u^{2}+v^{2}\right),
$$

where $C_{f}$ is a dimensionless coefficient which is typically less than 0.1. However, in order to avoid unusually lower basal traction when flow velocity is low, this formula is coupled with Coulomb failure criterion, and can be written as

$$
\tau_{\mathrm{b}}=\max \left(C_{f} \rho_{s}\left(u^{2}+v^{2}\right), \quad \rho g_{z} h(1-r) \tan \phi_{\text {bed }}\right),
$$

where $r=\rho_{f} \rho$ is density ratio; $\tau_{s}$ can be expressed as

$$
\tau_{s}=\left(\rho g_{z} h-p_{e}\right) \tan \phi_{s a t},
$$

where $\phi_{s a t}$ is the friction angle of the saturation bed; $P_{e}$ is the excess pore water pressure generated by the moving mass flow on top of the bed deposits. However, it is found that, when the moving velocity approximates to zero, the entrainment rate approaches infinity. In order to prevent this, the entrainment rate formula is modified as

$$
E=\frac{\tau_{b}-\tau_{s}}{\rho \sqrt{u^{2}+v^{2}}}\left(1-e^{-\xi\left(u^{2}+v^{2}\right)}\right),
$$

where $\xi$ is a constant coefficient. The value of $\xi$ is sensitive to the erosion rate. In order to obtain a reasonable value of $\xi$, the USGS experiment has been simulated. Simulation results indicate that the computed data agreed well with the experimental data by taking $\xi=$ 0.06 . The computed erosion rate (about $0.07 \sim 0.1 \mathrm{~m}^{3} / \mathrm{s}$ ) is also consistent with the experiment range (about $\left.0.05 \sim 0.1 \mathrm{~m}^{3} / \mathrm{s}\right)$. Hence, $\xi=0.06$ is used as a reasonable parameter. At the speed of $10 \mathrm{~m} / \mathrm{s}, e^{-\xi\left(u^{2}+v^{2}\right)}$ approaches 0 , and Eq. (9) reduces to the original entrainment rate formula.

\section{Excess pore water pressure model}

Landslide paths are typically covered by surficial deposits which may be loose, and have high water content (McDougall and Hungr 2005). Rapid loading by the weight of landslide may produce excess pore water pressure in the bed material. The excess pore water pressure is based on the Skempton formula and modified by
Sassa $(1985,1989)$ for undrained direct shear test. Assuming that the saturated soil at the base of a landslide is subjected to an undrained direct shear (Luna and Remaitre 2012),

$$
p_{e}=B_{D}\left(\Delta \sigma+A_{D} \Delta \tau\right),
$$

where $A_{D}$ and $B_{D}$ are excess pore pressure parameters in the undrained direct shear state. $A_{D}$ changes with the strain value, and $B_{D}$ is affected by the loaded stress level, and is very sensitive to the degree of saturation (Luna and Remaitre 2012). The normal stress and the shear strength caused by the landslide can be expressed as,

$$
\begin{aligned}
\Delta \sigma & =\rho(1-r) g_{z} h \\
\Delta \tau & =\rho(1-r) g_{c} h
\end{aligned}
$$

where $g_{c}=\sqrt{g_{x}^{2}+g_{y}^{2}}$ represents the component of gravitational acceleration along the tangential direction.

\section{The full model equations}

The complete set of dynamic model equations to simulate landslide over erodible surface are rewritten as follows:

$$
\begin{aligned}
& \frac{\partial h}{\partial t}+\frac{\partial h u}{\partial x}+\frac{\partial h v}{\partial y}=E \\
& \frac{\partial h u}{\partial t}+\frac{\partial}{\partial x}\left(h u^{2}+\frac{1}{2} k_{a p} g_{z} h^{2}\right)+\frac{\partial(h u v)}{\partial y} \\
& =u\left(z_{b}\right) E+g_{x} h-\operatorname{sgn}\left(\frac{\partial u}{\partial y}\right) k_{a p} h \frac{\partial\left(g_{z} h\right)}{\partial y} \sin \phi_{\text {int }}-\frac{u}{\sqrt{u^{2}+v^{2}}} \frac{\tau_{b}}{\rho}
\end{aligned}
$$

$$
\begin{aligned}
& \frac{\partial h v}{\partial t}+\frac{\partial(h u v)}{\partial x}+\frac{\partial}{\partial y}\left(h v^{2}+\frac{1}{2} k_{a p} g_{z} h^{2}\right) \\
& =v\left(z_{b}\right) E+g_{y} h-\operatorname{sgn}\left(\frac{\partial v}{\partial x}\right) k_{a p} h \frac{\partial\left(g_{z} h\right)}{\partial x} \sin \phi_{\text {int }}-\frac{v}{\sqrt{u^{2}+v^{2}}} \frac{\tau_{b}}{\rho}
\end{aligned}
$$

$$
\frac{\partial z}{\partial t}=-E
$$

The model equations (13)-(16) constitute a system of five equations with the variables $h, u, v$, and $E$ for landslide, as well as for mobile surface of landslide path $z$. Together with the initial and boundary conditions, the system constitutes a well posed set of equations describing landslide flow over erodible surface.

\section{Method}

The model equations are hyperbolic, and based on mass and momentum conservation; these properties make finding solutions difficult, because they can generate discontinuous and numerical oscillations in finite time. Otherwise, the nonlinear characteristics of the equations 
also limit the applicable range of the analytical solutions. Therefore, the numerical method should be able to eliminate these effects. However, the exact solution of the Riemann problem is less efficient. In recent years, a number of approximate Riemann solvers have been developed to solve the Riemann problem in an efficient manner, including the method of characteristics (Katopodes and Strelko 1978; Iwasaki and Inutsuka 2011), the finite difference method (Fennema and Chaudhry 1990; Jha et al. 1995; Ouyang et al. 2014), and the finite volume method (Zoppou and Roberts 2000; Fraccarollo et al. 2003; Brufau et al. 2004; Gottardi and Venutelli 2004; Toro 2009; Fayssal and Moukalled 2012). In this paper, the finite volume method and Roe's approximation scheme are used to solve the debris flow problem. In order to improve the feasibility of this model, we also used the fractional step method (Gottardi and Venutelli 2004; Liang et al. 2006). For convenience, the model equations (13)-(16) can be written in vector format as given below:

$$
\frac{\partial \mathbf{U}}{\partial t}+\frac{\partial \mathbf{F}}{\partial x}+\frac{\partial \mathbf{G}}{\partial x}=\mathbf{S}+\mathbf{T}
$$

in which,

$$
\begin{aligned}
& \mathbf{U}=\left(\begin{array}{c}
h \\
h u \\
h v \\
z
\end{array}\right)^{T} ; \quad \mathbf{F}=\left(\begin{array}{c}
h u \\
h u^{2}+\frac{1}{2} g_{z} k_{a p} h^{2} \\
h u v \\
0
\end{array}\right)^{T} ; \quad \mathbf{G}=\left(\begin{array}{c}
h v \\
h u v \\
h v^{2}+\frac{1}{2} g_{z} k_{a p} h^{2} \\
0
\end{array}\right)^{T} ; \\
& \mathbf{S}=\left(\begin{array}{c}
u\left(z_{b}\right) E+g_{x} h-\frac{u \tau_{b}}{\rho \sqrt{u^{2}+v^{2}}}-\operatorname{sgn}\left(\frac{\partial \nu}{\partial x}\right) k_{a p} h \frac{\partial\left(g_{z} h\right)}{\partial x} \sin \phi_{\text {int }} \\
-E
\end{array}\right) \text {; } \\
& \mathbf{T}=\left(\begin{array}{c}
0 \\
0 \\
v\left(z_{b}\right) E+g_{x} h-\frac{v \tau_{b}}{\rho \sqrt{u^{2}+v^{2}}}-\operatorname{sgn}\left(\frac{\partial u}{\partial y}\right) k_{a p} h \frac{\partial\left(g_{z} h\right)}{\partial y} \sin \phi_{\mathrm{int}}
\end{array}\right) .
\end{aligned}
$$

Eq. (17) can be divided into two separate, onedimensional problems based on the operator-splitting technique as,

$$
\begin{aligned}
& \frac{\partial \mathbf{U}}{\partial t}+\frac{\partial \mathbf{F}}{\partial x}=0, \\
& \frac{\partial \mathbf{U}}{\partial t}+\frac{\partial \mathbf{G}}{\partial y}=0 .
\end{aligned}
$$

This solution can then be obtained by

$$
\mathbf{U}^{n+1}=L_{x}\left(\frac{d t}{2}\right) L_{y}\left(\frac{d t}{2}\right) L_{y}\left(\frac{d t}{2}\right) L_{x}\left(\frac{d t}{2}\right) \mathbf{U}^{n}
$$

where $L_{x}$ and $L_{y}$ represent the operators in the $x$ and $y$ directions, respectively (Liang et al. 2006; Ouyang et al.
2013). The fractional step method is used to improve calculation stability. Taking $L_{x}$ as an example, the discretization scheme is given by the following steps:

Step 1: Solve the homogeneous shallow water equations,

$$
\frac{\partial \mathbf{U}}{\partial t}+\frac{\partial \mathbf{F}}{\partial x}=0
$$

Its corresponding discretization form based on the finite volume method is written as,

$$
\mathbf{U}_{i}^{\mathrm{n}+1}=\mathbf{U}_{i}^{n}+\frac{\Delta t}{\Delta x}\left(\mathbf{F}_{i+1 / 2}^{n}-\mathbf{F}_{i-1 / 2}^{n}\right),
$$

where $\mathbf{F}_{i+1 / 2}^{n}$ and $\mathbf{F}_{i-1 / 2}^{n}$ are numerical fluxes. In Roe's approximation, the nonlinear problem is linearized at the cell interface. At the cell interface, we have a discontinuity with state $\mathbf{U}_{L}$ on the left side, and state $\mathbf{U}_{R}$ on the right side. In addition, we couple the MUSCL approach with Roe scheme to reconstruct the interface data $\boldsymbol{U}_{L}$ and $\boldsymbol{U}_{R}$ for obtaining a high level of accuracy, and avoiding spurious oscillations (Liang et al. 2006; Ouyang et al. 2013). Hence, the numerical flux can be expressed as

$$
\mathbf{F}_{i+1 / 2}^{n}=\frac{1}{2}\left[\mathbf{F}_{R}+\mathbf{F}_{L}-|\mathbf{J}|\left(\mathbf{U}_{R}-\mathbf{U}_{L}\right)\right],
$$

where $\mathbf{F}_{L}$ and $\mathbf{F}_{R}$ are calculated from $\mathbf{U}_{L}$ and $\mathbf{U}_{R}$, repetitively; J represents the Jacobian matrix of $\mathbf{F}$. With Roe's approximation, Eq. (20) can be expressed as,

$$
\mathbf{F}_{i+1 / 2}^{n}=\frac{1}{2}\left[\mathbf{F}_{R}+\mathbf{F}_{L}-\sum_{m=1}^{2}\left(\left|\lambda^{m}\right| \alpha^{m} \gamma^{m}\right)\right],
$$

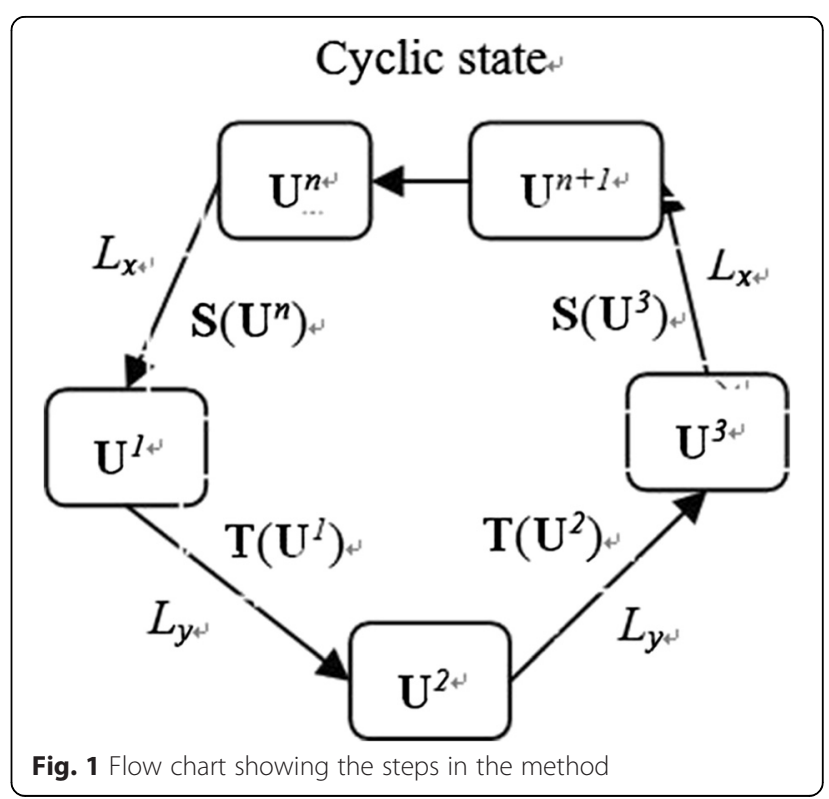




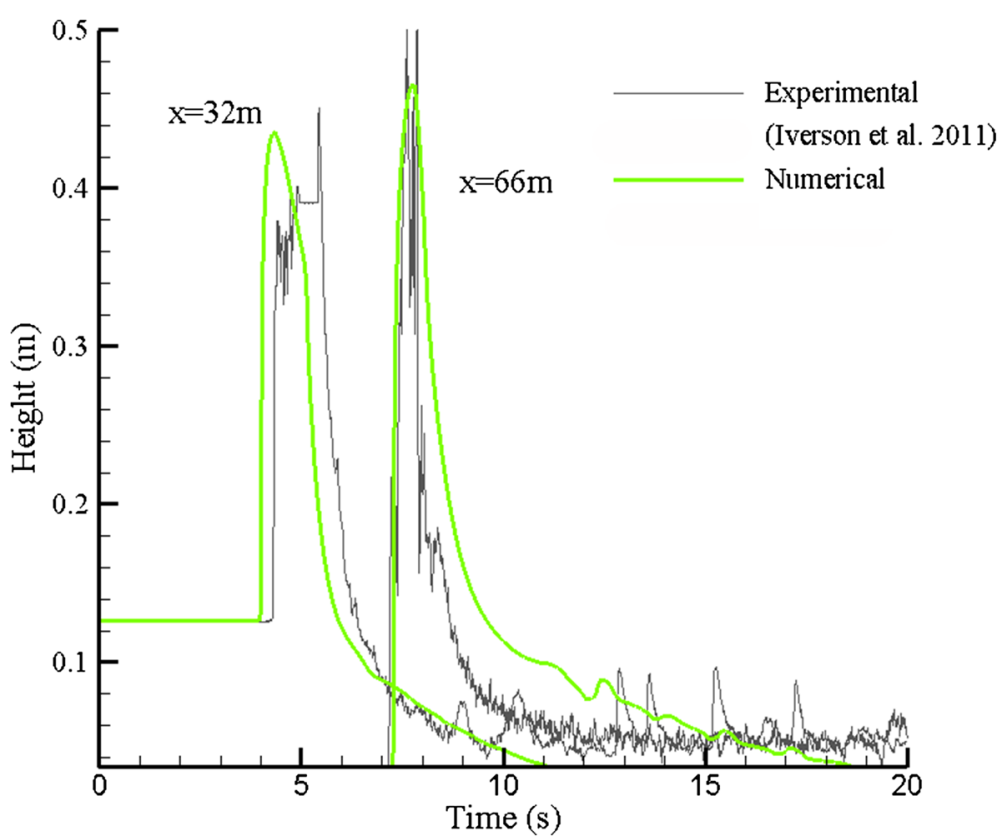

Fig. 2 Comparison of flow height and time curve with flume experiment of entraining fully saturated sediment at location $x=32 \mathrm{~m}$ and $x=66 \mathrm{~m}$

where $\gamma$ is the eigenvector of $\mathbf{J} ; \lambda$ represents the corresponding eigenvalues. The symbol $\alpha$ represents the wave strength. All of them are evaluated at the average state $h_{a g}, u_{a g}$ and $c_{a g}$. The expreesion for $h_{a g}, u_{a g}$ and $c_{a g}$ can be obtained from, $h_{a g}=\sqrt{h_{L} h_{R}}, \quad u_{a g}=\frac{\sqrt{h_{R}} u_{R}+\sqrt{h_{L}} u_{L}}{\sqrt{h_{R}}+\sqrt{h_{L}}}, c_{a g}=\sqrt{\frac{1}{2} k_{a p} g_{z}\left(h_{R}+h_{L}\right)}$.

Step 2: Solve the source term,

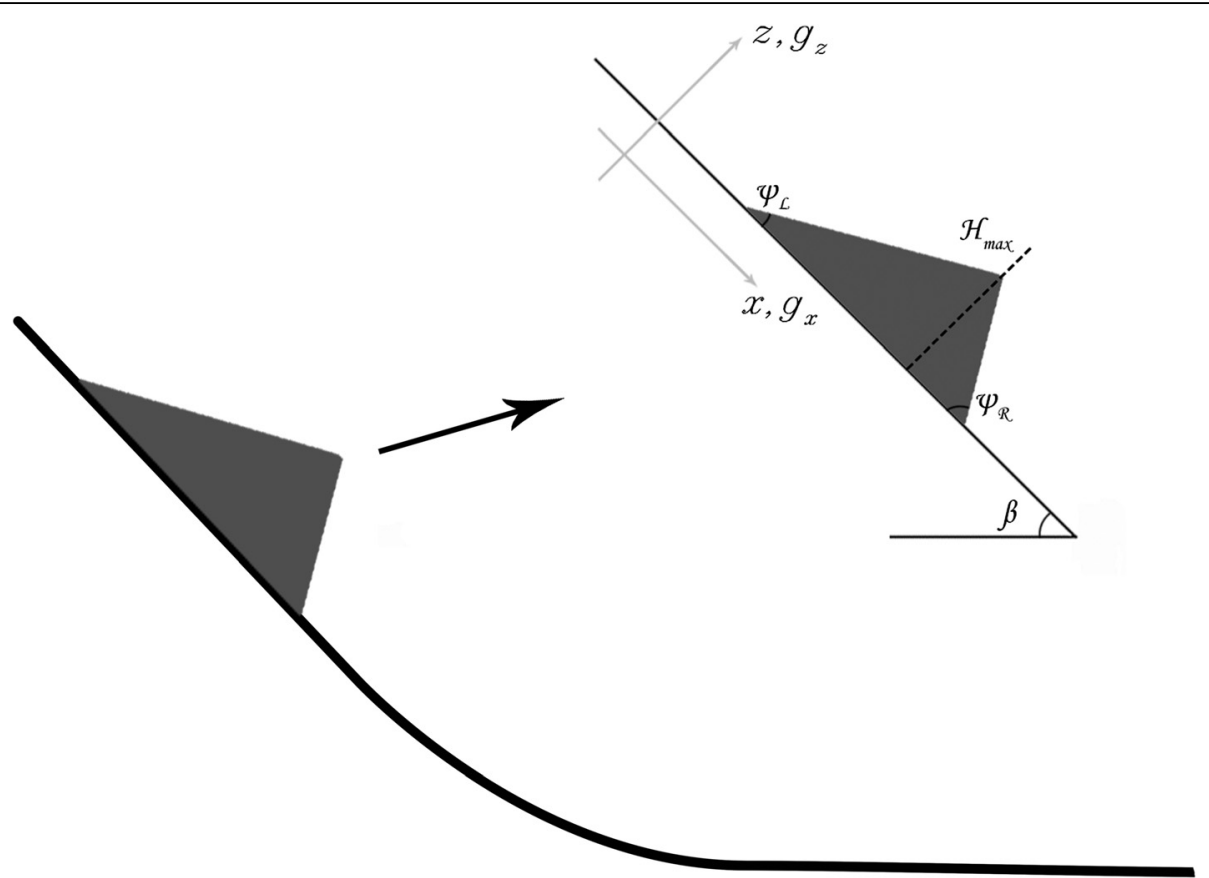

Fig. 3 A simple sketch of channel and landslide. Initially, the angles between landslide and channel are set as $\psi_{\mathrm{L}}=30^{\circ}$ and $\psi_{\mathrm{R}}=60^{\circ}$, and the maximum height of landslide $H_{\max }=0.5 \mathrm{~m}$. The channel is $10 \mathrm{~m}$ long, and the inclined component of channel $\left(\beta=30^{\circ}\right)$ lies in the range $x<4 \mathrm{~m}$, the horizontal component of channel lies in the range $x>5 \mathrm{~m}$ and a circular arc transition zone smoothly joins the two regions 
Table 1 Parameters used in numerical experiments

\begin{tabular}{lll}
\hline Symbol & & Values \\
\hline$\rho_{s}$ & Density of solid & $2700 \mathrm{~kg} / \mathrm{m}^{3}$ \\
$\rho_{f}$ & Density of fluid & $1000 \mathrm{~kg} / \mathrm{m}^{3}$ \\
$c$ & Solid volume fraction & 0.6 \\
$\varphi_{\text {int }}$ & The angle of internal friction & $40^{\circ}$ \\
$\varphi_{\text {bed }}$ & The angle of base friction & $40^{\circ}$ \\
$\varphi_{\text {sat }}$ & The angle of friction of saturation bed & $35^{\circ}$ \\
$A_{D}$ & Excess pore water pressure parameter & 0.6 \\
$B_{D}$ & Excess pore water pressure parameter & 1 \\
$C_{f}$ & Dimensionless coefficient & 0.015 \\
\hline
\end{tabular}

$$
\frac{\partial \mathbf{U}}{\partial t}=\mathbf{S}
$$

A semi-implicit scheme is used to discretize Eq. (22) as,

$$
\frac{\mathbf{U}_{i}^{n+1}-\mathbf{U}_{i}^{*}}{\Delta t}=\mathbf{S}_{i}^{*}
$$

where $\mathbf{U}_{i}^{*}$ and $\mathbf{S}_{i}^{*}$ are obtained from Step 1 . The stability criterion adopted here is expressed by,

$$
\Delta t \leq \min \left(c f l \frac{d x}{\max \left(\sqrt{u^{2}+v^{2}}+c m\right)}\right)
$$

where $c f l$ is Courant number, and is less than $1 ; d x$ is distance from the centroid of the cell; and $\mathrm{cm}$ can be expressed as $\mathrm{cm}=\sqrt{k_{a p} g_{z} h}$.

A flow chart showing all the steps in this method is shown in Fig. 1. $L_{x}$ and $L_{y}$ have the same treatment. Each operator is operated twice to obtain the solution at the next step. Each step uses the state of $\mathbf{U}$ obtained from the previous step.

\section{Results and discussion}

The purpose of this section is to analyse the numerical results of four tests in detail, and to show the effects of excess pore water pressure and erosion on the dynamic process of landslide. We assumed that the composition of the bed sediment is the same as that of the landslide, and that the eroded material and landslide can mix together rapidly. Hence, $c$ is kept constant in the whole computation. The bottom velocities $u\left(z_{b}\right)$ and $v\left(z_{b}\right)$ are considered as one-tenth of the velocity of the landslide. Moreover, free boundary conditions are imposed on each side of the computational domain, and the Courant number is set as $c f l=$ 0.7 . The gravitational acceleration is $g=9.8 \mathrm{~m} / \mathrm{s}^{2}$.

\section{Test 1: Numerical comparisons with USGS flume experiments}

To verify the ability of the current model to accurately portray landslide dynamics over erodible beds, a comparison
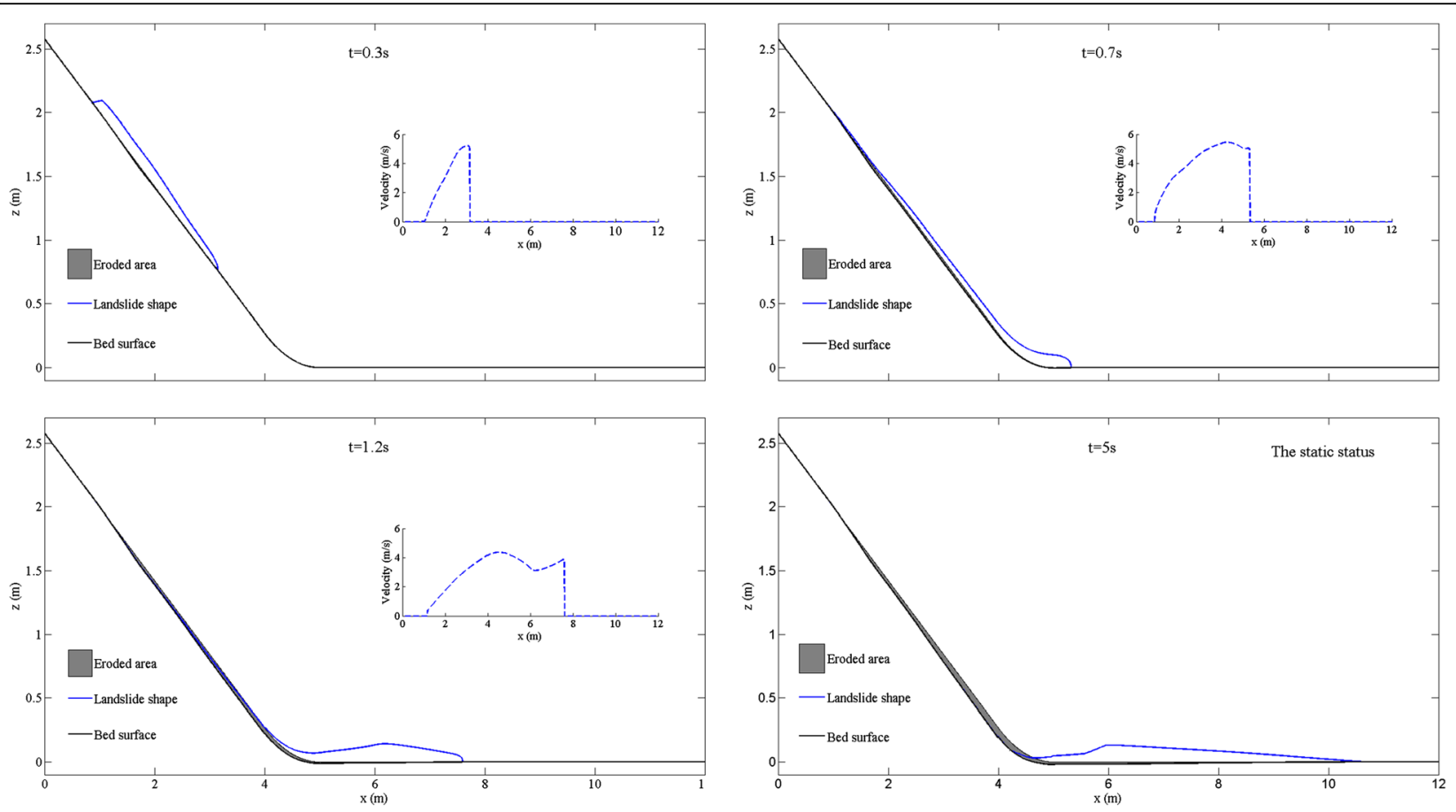

Fig. 4 Four specific moments as $t=0.3 \mathrm{~s}, 0.7 \mathrm{~s}, 1.2 \mathrm{~s}$, and $5 \mathrm{~s}$ are selected to show the downslope motion of landslide. The blue line represents the landslide profile and the gray area represents the eroded zone. The black line represents the eroded slope. The small picture represents the velocity of landslide 


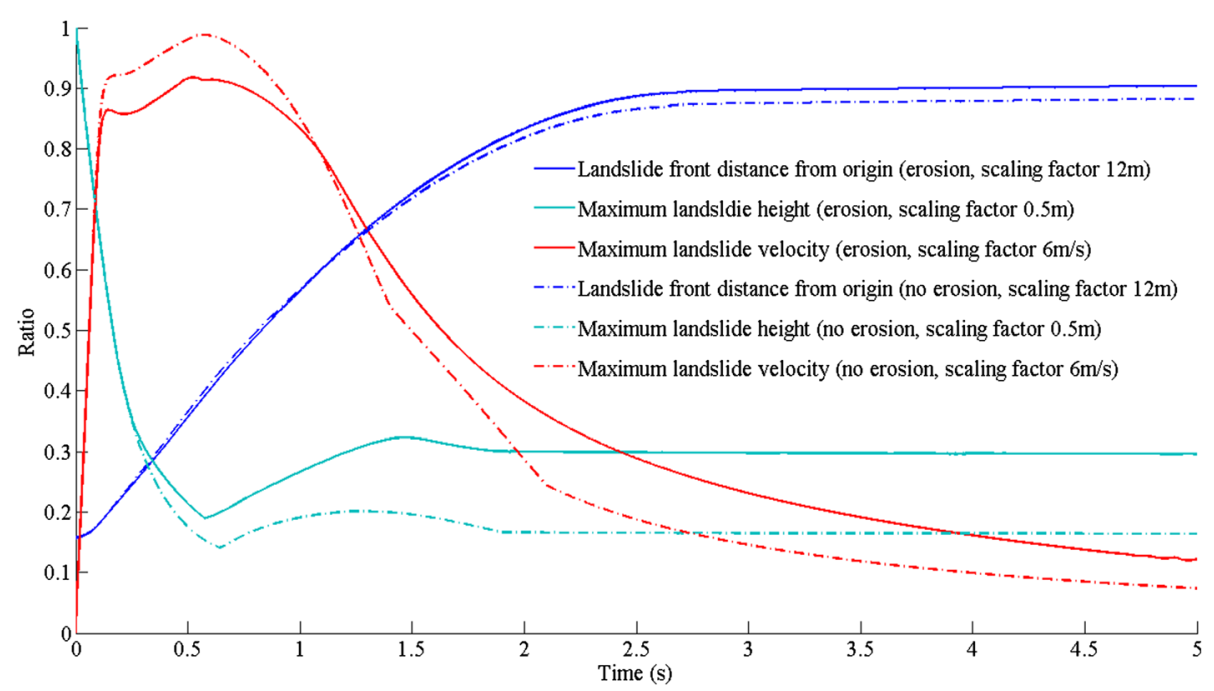

Fig. 5 Simulation of location of landslide front, maximum landslide height, and velocity with increase of time (with erosion and without erosion)

of numerical computational results with USGS flume experiment results was performed. The description of mass flow experiments on erodible bedspread is summarized by Iverson et al. (2011). According to Iverson et al. (2011), the bed material in the experiment is saturated, and has a small cohesion, typically less than 400 . Thus, it is reasonable to set $A_{D}=0.9$ and $B_{D}=1$ for the numerical simulation. The values of other parameters are set to be the same as the measured values from Iverson et al. (2011). Comparison of numerical solutions and experimental results of flow height versus time is shown in Fig. 2. It shows that the numerically obtained result of flow height versus time basically agrees well with the experimental results. The erosion rate calculated by the current model is about $0.07 \sim 0.1 \mathrm{~m}^{3} / \mathrm{s}$, which is generally consistent with the range obtained in the experiment, which is $0.05 \sim 0.1 \mathrm{~m}^{3} / \mathrm{s}$.

\section{Test 2: Simulation of the dynamic process of landslide over erodible bed}

In this subsection, model equations are integrated for a simple flow configuration, in which a landslide is released from a triangular dam, and moves down an inclined channel (shown in Fig. 3). Initially, the angles between the landslide and the channel are set as $\psi_{\mathrm{L}}=30^{\circ}$ and $\psi_{\mathrm{R}}=60^{\circ}$, and the maximum height of the landslide is set at $\mathrm{H}_{\max }=0.5 \mathrm{~m}$. The channel is $10 \mathrm{~m}$ long, and the inclined component of channel $\left(\beta=30^{\circ}\right)$ lies in the range $x<4 m$; the horizontal component of channel lies in the range $x>5 \mathrm{~m}$; a circular arc transition zone smoothly joins the two regions. The distance from the centroid of the cell is set as $d x=0.05 \mathrm{~m}$. Values of the relevant parameters are listed in Table 1 . The pore pressure parameters used were $A_{D}=0.6$, and $B_{D}=0.9$. These values correspond to the bed sediment that has a high degree of saturation. Four specific moments of the simulation results, at $t=0.3 \mathrm{~s}$, $0.7 s, 1.2 s$, and $5 s$ are shown in Fig. 4. As the landslide accelerates and spreads out rapidly in the downslope direction, the erosion gradually becomes significant. An interesting phenomenon that could be noticed is that the velocity of falling is higher at the corner. Due to the increasing frictional resistance when the landslide is passing around the corner into the ground, the front part of landslide enters the stage of accumulation, and the latter part of landslide is subjected to extra resistance from the former part.

The impact of erosion on the dynamic process of landslide was also investigated. We performed two numerical tests, with and without erosion, under the same conditions. In order to highlight the difference between the dynamic processes of the two numerical tests more clearly, the position of the front of the landslide as it descends on an incline, as well as the velocity and the maximum height during the run, are shown in Fig. 5. The simulation results of the two numerical tests show some similar overall characteristics. The maximum velocity of the landslide with erosion is higher than that without erosion, and leads to a longer distance of movement, an increased front distance from the origin. It indicates that erosion can enhance the mobility of a landslide. The maximum landslide height with erosion is more than that without erosion, and the overall velocity decreases more gradually.

Table 2 Values of coefficients $B_{D}$ and $A_{D}$

\begin{tabular}{llccc}
\hline Symbol & Group 1 & Group 2 & Group 3 & Group 4 \\
\hline$A_{D}$ & 0 & 0.2 & 0.6 & 0.6 \\
$B_{D}$ & 0 & 0.6 & 0.2 & 0.6 \\
\hline
\end{tabular}




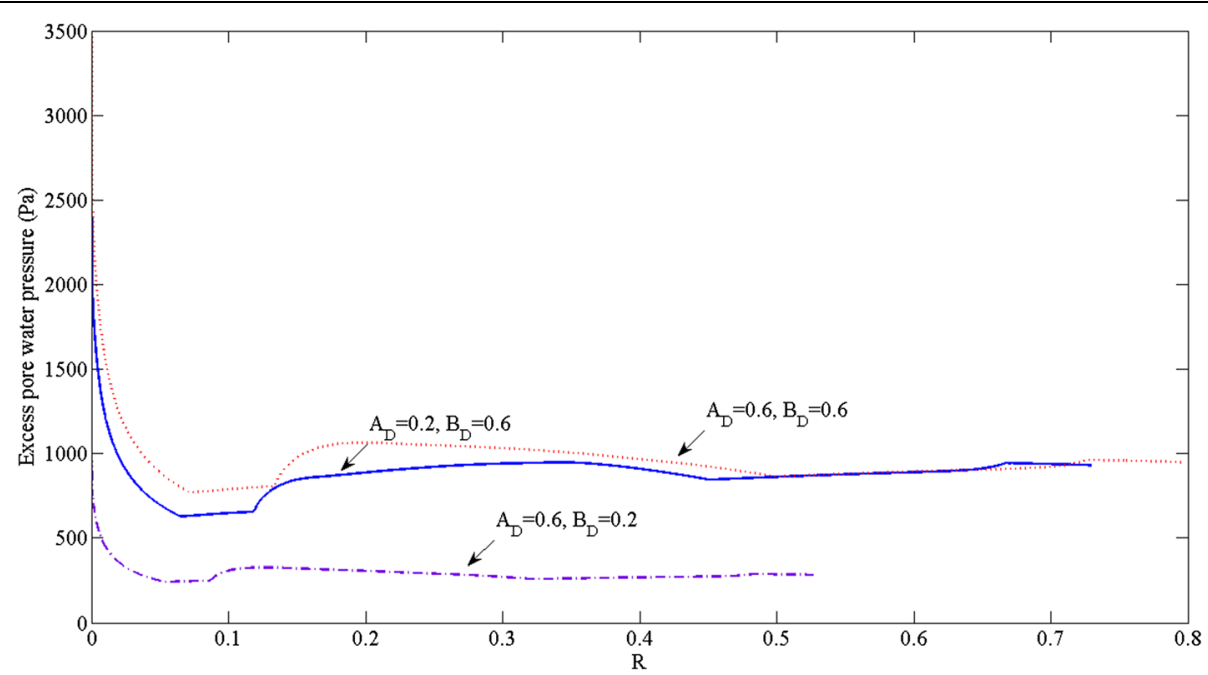

Fig. 6 Relationship between the evolution of pore water pressure coefficients and erosion degree

\section{Test 3: Analysis of the effect of excess pore water} pressure

In this section, we investigate the effect of excess pore water pressure on the motion of the landslide, and the erosion process. The initial condition of the landslide and the channel are the same as in test 2 . We define $R$, which represents the degree of erosion, as $R=E t / \mathrm{Vol}$, where $E t$ is the amount of erosion, and $\mathrm{Vol}$ is initial volume of landslide; and $V o l=0.29 \mathrm{~m}^{3}$. Different values of the coefficients $B_{D}$ and $A_{D}$ have been chosen, and are shown in Table 2. The relationship between the evolution of maximum of excess pore water pressure and $R$ is shown in Fig. 6. Similar behaviours are exhibited during the slide process. It shows that the excess pore water pressure decreases at first because of the deformation of landslide and the decrease in height of the landslide. With the accumulation of landslide, the height of the landslide increases, and this leads to a rise in excess pore water pressure. With the higher values of $A_{D}$ and $B_{D}$, the excess pore water pressure is rising faster, and this reduces the resistance to shear stress from the erodible bed, and leads to a higher erosion amount and longer moving distance of the landslide.

In order to further investigate the effect of excess pore water pressure on the erosion, sensitivity analysis was performed for $A_{D}$ and $B_{D}$. The result of $R$ versus different values of $A_{D}$ and $B_{D}$ is shown in Fig. 7. It shows that the erosion amount changes with different values of $A_{D}$ and $B_{D}$. The sensitivity difference between $A_{D}$ and $B_{D}$ is evident, and the erosion amount is more sensitive to $B_{D}$. A significant phenomenon that should be noticed is that the erosion amount increases almost linearly with change in $A_{D}$ and $B_{D}$. For example, with a constant value of

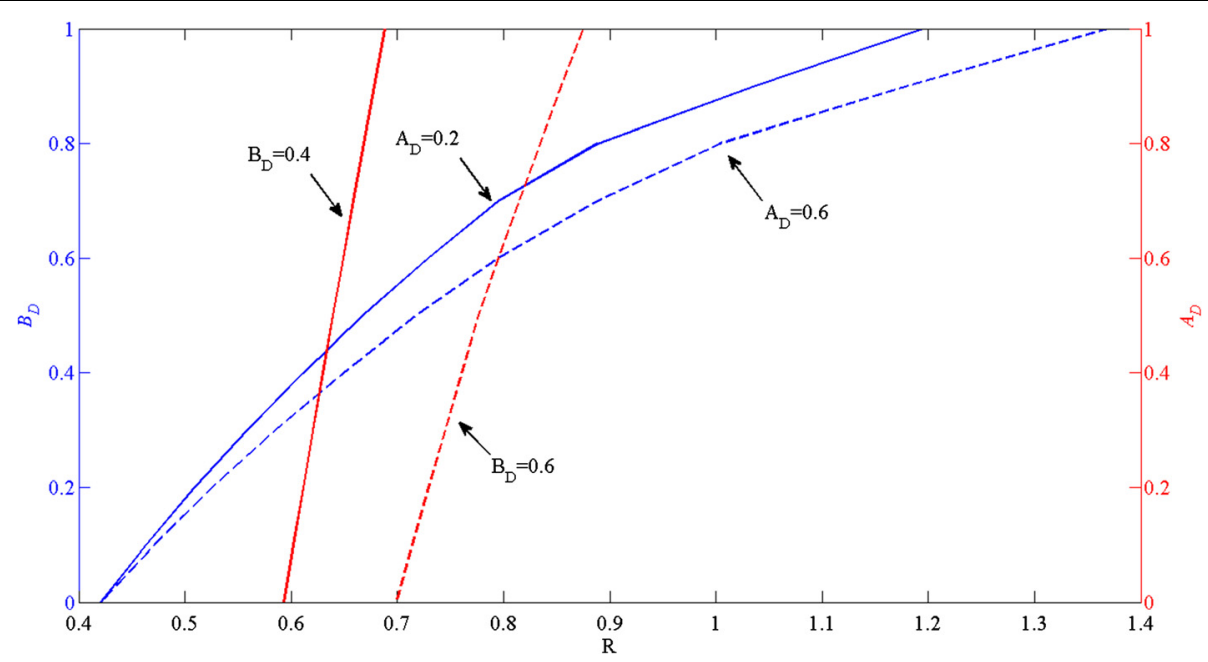

Fig. 7 The curve of $R$ versus different values of $A_{D}$ and $B_{D}$ 


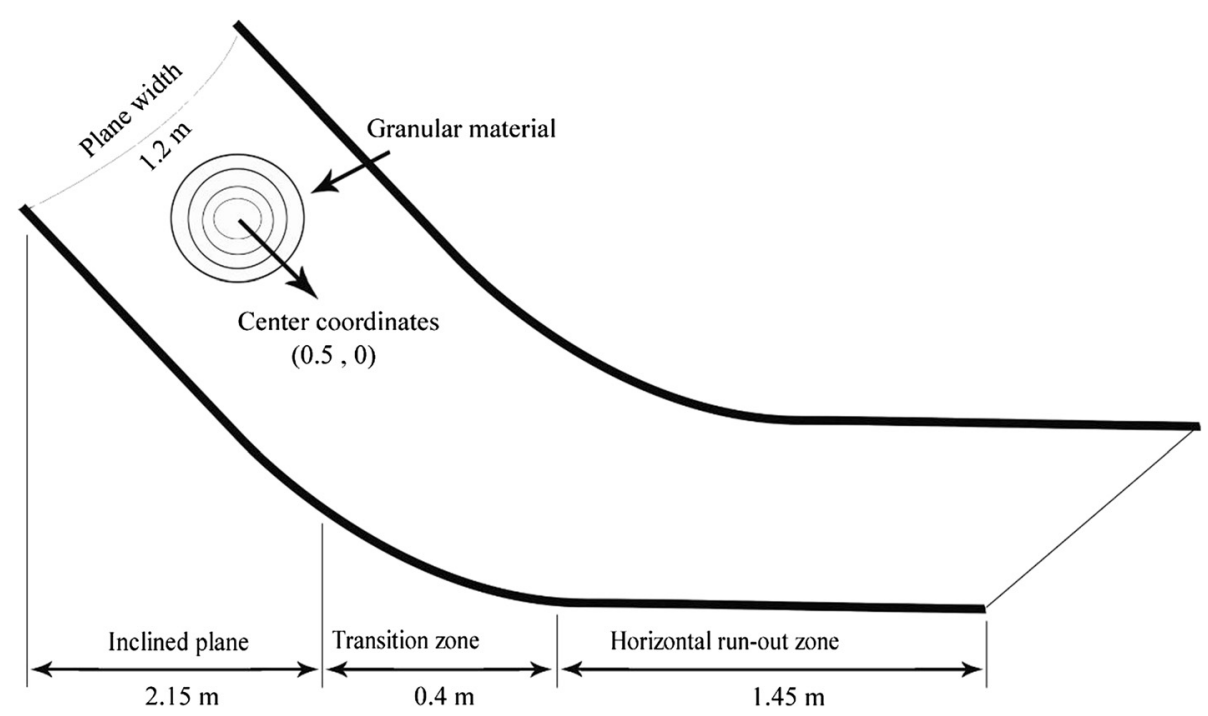

Fig. 8 Simple sketch of channel and landslide. The channel consists of an inclined plane $\left(\psi=40^{\circ}, x<215 \mathrm{~cm}\right)$, a horizontal run-out zone $(x>255 \mathrm{~cm})$ and a transition zone joining the two regions. Superimposed on the inclined section of the chute is a shallow parabolic cross-slope topography $\left(y^{2} / 2 b\right.$ with $b=110 \mathrm{~cm}$ ). The granular material is released from rest on the parabolic inclined section of the chute by means of a Perspex cap. The cap is fitted to the basal chute topography and has a spherical free surface. The major axis of the cap is $32 \mathrm{~cm}$ in length, and the maximum height of the cap above the reference surface is $22 \mathrm{~cm}$

$B_{D}=0.6$, the ratio of erosion amount increases by $0.022 \%$ when $A_{D}$ increases by 0.1 . With a constant value of $A_{D}=$ 0.2 , the ratio of erosion amount increases by $0.1 \%$ when $B_{D}$ increases by 0.1 , for values of $B_{D}$ less than 0.5 . The ratio of erosion amount increases faster $(0.15 \%)$ when $B_{D}$ increases by 0.1 , for values of $B_{D}$ greater than 0.5 .

\section{Test 4: Simulation of two-dimensional landslide over erodible bed}

The model is applied to simulate the 2-D landslide dam over mobile bed to demonstrate its potential for simulating a practical case. A sketch showing the chute and landslide is shown in Fig. 8. In this test, a simple reference surface is defined, which consists of an inclined plane $\left(\psi=40^{\circ}, x<215 \mathrm{~cm}\right)$, a horizontal run-out zone $(x>255$ $\mathrm{cm}$ ), and a transition zone joining the two regions. Superimposed on the inclined section of the chute, is a shallow parabolic cross-slope topography $\left(y^{2} / 2 b\right.$ with $\left.b=110 \mathrm{~cm}\right)$. The granular material is released from rest on the parabolic inclined section of the chute by means of a Perspex cap that opens rapidly $(t=0 \mathrm{~s})$. The cap is fitted to the basal chute topography and has a spherical free surface. The major axis of the cap is $32 \mathrm{~cm}$ in length, and the
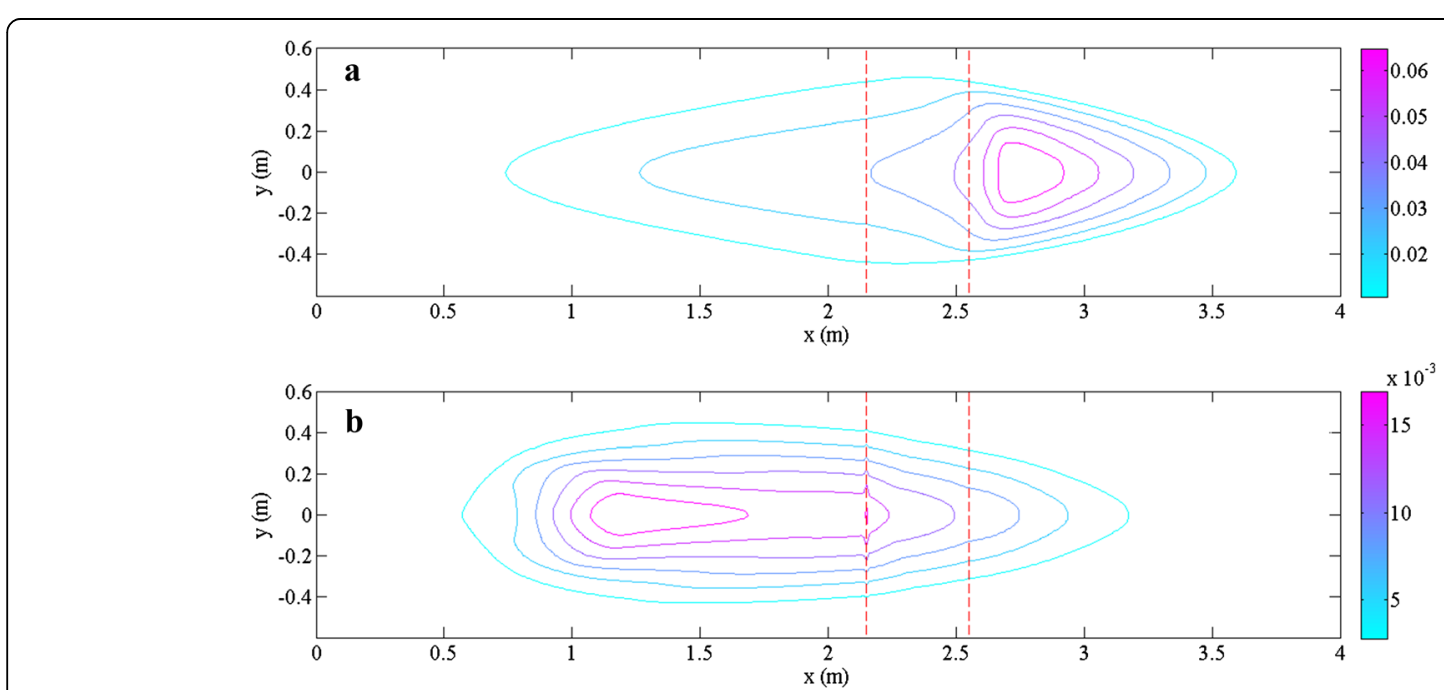

Fig. 9 a The shape of landslide and (b) the eroded bed caused by landslide. The red lines at $x=2.15 \mathrm{~m}$ and $x=2.55 \mathrm{~m}$ indicate the position of the transition zone joining the two slope regions 
maximum height of the cap above the reference surface is $22 \mathrm{~cm}$. The values of the parameters used are the same as in test 2. The motion status of the landslide and the eroded degree of bed at $t=1 \mathrm{~s}$ are shown in Fig. 9. The red lines at $x=2.15 \mathrm{~m}$ and $x=2.55 \mathrm{~m}$ indicate the position of the transition zone joining the two slope regions. The landslide shape and the erosion degree are well captured. A slight jump of erosion occurs around $2.15 \mathrm{~m}$ due to the continuous erosion by latter part of the landslide in the accumulation process, and the degree of erosion. The numerical results are in agreement with the reality, and thus, the applicability of the present model is proved.

\section{Conclusion}

In this paper, a physics-based dynamic model based on Savage-Hutter theory for landslide has been presented. The effects of entrainment and excess pore water pressure on the dynamic process of landslide are considered. The entrainment rate model satisfying the boundary momentum conservation condition and the excess pore water pressure model based on the Skempton's equations have been introduced in the present model. A high-precision calculation method was proposed to solve the model equations. Finally, four numerical tests were performed to simulate landslide dynamics over erodible surface. The evolution of entrainment volume, velocity, travel distance, and excess pore water pressure of landslide, as well as hazard zone, can be predicted simultaneously. Numerical results indicate that erosion enhances the destructive power, and enlarged the hazard area of a landslide, and the evolution of excess pore water pressure of bed material causes a change in the erosion amount, further influencing the dynamic process of landslide. It is seen that the relevant parameters have a significant impact on the evolution of excess pore water pressure; however, the degree of saturation of bed sediment has the highest influence on excess pore water pressure. These findings are consistent with observable phenomena in natural landslide. However, more precise and complete experiments are needed to verify and improve the theoretical model to reflect the process of landslide more realistically.

\section{Competing interests}

The authors declare that they have no competing interests.

\section{Authors' contributions}

LW carried out numerical modelling and manuscript preparation. HSM provided suggestions and advice to the study and checked the manuscript. All authors read and approved the final manuscript.

\section{Acknowledgment}

The authors thank two anonymous reviewers for helpful suggestions. This research has received financial support from the NSFC (Grant No. 41272346, 41101008), the National Key Basic Research Program of China (2013CB733201) and the STS project of Chinese Academy of Sciences (project No. KFJ-EW-STS-094).

\section{Author details}

'Key laboratory of Mountain Hazards and Surface Process, Chinese Academy of Sciences, Chengdu 610041, China. Institute of Mountain Hazards and Environment (IMHE), Chinese Academy of Sciences, Chengdu 610041, China.

${ }^{3}$ Center for Excellence in Tibetan Plateau Earth Sciences, Chinese Academy of Sciences, Beijing 100101, China.

Received: 13 October 2014 Accepted: 29 July 2015

Published online: 06 August 2015

\section{References}

Agliardi F, Crosta GB, Frattini P (2009) Integrating rockfall risk assessment and countermeasure design by 3D modelling techniques. Natural Hazards Earth Syst Sci 9:4

Brufau P, García-Navarro P, Vázquez-Cendón ME (2004) Zero mass error using unsteady wetting-drying conditions in shallow flows over dry irregular topography. Int J Numer Methods Fluids 45(10):1047-1082

Crosta GB, Imposimato S, Roddeman DG (2003) Numerical modelling of large landslides stability and run-out. Nat Hazards Earth Syst Sci 3:523-538

Chen H, Lee CF (2000) Numerical simulation of debris flows. Can Geotech 」 37:146-160

Cao Z, Pender G, Wallis S, Carling P (2004) Computational dam-break hydraulics over erodible sediment bed. J Hydraul Eng 130(7):689-703

De Blasio FV, Elverhøi A (2008) A model for frictional melt production beneath large rock avalanches. J Geophysical Res Earth Surface (2003-2012) 113:F2

Fennema RJ, Chaudhry MH (1990) Explicit methods for 2-D transient free-surface flows. J Hydraul Eng 116(8):1013-1034

Fraccarollo L, Capart H (2002) Riemann wave description of erosional dam-break flows. J Fluid Mech 461:183-228

Fraccarollo L, Capart H, Zech Y (2003) A Godunov method for the computation of erosional shallow water transients. Int J Numer Methods Fluids 41(9):951-976

Fayssal I, Moukalled F (2012) A New Numerical Approach for Predicting the Two-Phase Flow of Refrigerants during Evaporation and Condensation. Numerical Heat Transfer Part B Fundamentals 62(5):341-369

George DL, Iverson RM (2011) A two-phase debris-flow model that includes coupled evolution of volume fractions, granular dilatancy, and pore-fluid pressure. Italian J Eng Geol Environ 10:2011-03, In press, Doi

Gerolymos N, Gazetas G (2007) A model for grain-crushing-induced landslidesApplication to Nikawa, Kobe 1995. Soil Dyn Earthq Eng 27(9):803-817

Goren L, Aharonov E (2007) Long runout landslides: the role of frictional heating and hydraulic diffusivity. Geophys Res Lett 34:7

Goren L, Aharonov E (2009) On the stability of landslides: A thermo-poro-elastic approach. Earth Planet Sci Lett 277:365-372

Gottardi G, Venutelli M (2004) Central scheme for two-dimensional dam-break flow simulation. Adv Water Resour 27:259-268

Gray JMNT (1999) Gravity-driven free surface flow of granular avalanches over complex basal topography. Proceedings of the Royal Society of London. Series A:Math Physical Eng Sci 455(1985):1841-1874

Hungr O, Corominas J, Eberhardt E (2005) Estimating landslide motion mechanism, travel distance and velocity. Proc. Int. Conf. on Landslide Risk Management, Vancouver, Canada. - Balkema, Leiden, 99-128

Hutter K, Luca I (2012) Two-layer debris mixture flows on arbitrary terrain with mass exchange at the base and the interface. Contin Mech Thermodyn 24(4-6):525-555

Iwasaki K, Inutsuka S (2011) Smoothed particle magnetohydrodynamics with a Riemann solver and the method of characteristics. Mon Not R Astron Soc 418(3):1668-1688

Iverson RM (2009) Elements of an Improved Model of Debris-flow Motion. Powders and Grains, Proc. 6 Intl. Conf. on Micromechanics of Granular Media, edited by M. Nakagawa and S. Luding Am Inst Physics Proc 1145(1):9-16

Iverson RM, Denlinger RP (2001) Flow of variably fluidized granular masses across three-dimensional terrain: 1. Coulomb mixture theory. J Geophysic Res Solid Earth (1978-2012) 106(B1):537-552

Iverson RM (2012) Elementary theory of bed-sediment entrainment by debris flows and avalanches. J Geophysic Res Earth Surface (2003-2012) 117:F3

Iverson RM, Reid ME, Logan M, LaHusen RG, Godt JW, Griswold JP (2011) Positive feedback and momentum growth during debris-flow entrainment of wet bed sediment. Nat Geosci 4:116-121

Iverson RM, Ouyang C (2014) Bed-sediment entrainment by rapidly evolving flows at Earth's surface: Review and reformulation of depth-integrated theory. Rev. Geophys. 
Jha AK, Akiyama J, Ura M (1995) First- and Second-order flux difference splitting schemes for dam-break problem. Am Society of Civil Eng J Hydraulic Eng 121(12):877-884

Katopodes N, Strelko T (1978) Computing two-dimensional dam-break flood waves. J Hydraul Div 104(9):1269-1288

Liang DF, Falconer RA, Lin B (2006) Comparison between TVD-MacCormack and ADI-type solvers of the shallow water equations. Adv Water Resour 29(12):1833-1845

Luna BQ, Remaitre A (2012) Analysis of debris flow behavior with a one dimensional run-out model incorporating entrainment. Eng Geol 128:63-75

McDougall S, Hungr O (2005) Dynamic modelling of entrainment in rapid landslides. Can Geotech J 42(5):1437-1448

McDougall S, Hungr O (2004) A model for the analysis of rapid landslide motion across three dimensional terrain. Can Geotech J 41:1084-1097

Ouyang C, He S, Xu Q, Luo Y, Zhang W (2013) A MacCormack-TVD finite difference method to simulate the mass flow in mountainous terrain with variable computational domain. Comput Geosci 52:1-10

Ouyang C, He S, Xu Q (2014) MacCormack-TVD Finite Difference Solution for Dam Break Hydraulics over Erodible Sediment Beds. J Hydraulic Eng. 141(5):06014026

Pudasaini SP, Hutter K (2007) Avalanche Dynamics. Springer, Berlin, Heidelberg

Pudasaini SP, Eckart W, Hutter K (2003) Gravity-driven rapid shear flows of dry granular masses in helically curved and twisted channels. Math Models Methods Appl Sci 13(7):1019-1052

Pitman EB, Nichita CC, Patra A, Bauer A, Sheridan M, Bursik M (2003) Computing granular avalanches and landslides. Phys Fluids 15(12):3638-3646

Pitman EB, Le L (2005) A two-fluid model for avalanche and debris flows. Philos Trans R Soc A Math Phys Eng Sci 363(1832):1573-1601

Sassa K (1985) The mechanism of debris flows. In: Proceedings of the 11th International Conference on Soil Mechanics and Foundation Engineering, San Francisco. International Society of. Soil Mech Foundation Eng 1:1173-1176

Sassa K (1989) Geotechnical model for the motion of landslides. International Journal of Rock Mechanics and Mining Sciences and Geomechanics Abstracts. Elsevier Sci 26(2):88-88

Savage SB, Hutter K (1989) The motion of a finite mass of granular material down a rough incline. J Fluid Mech 199:177-215

Savage SB, Iverson RM (2003) Surge dynamics coupled to pore-pressure evolution in debris flows. Debris-flow Hazards Mitigation Mech Prediction Assess 1:503-514

Toro EF (2009) Riemann solvers and numerical methods for fluid dynamics: a practical introduction. Springer Science \& Business Media.

Vardoulakis I (2000) Catastrophic landslides due to frictional heating of the failure plane. Mech Cohesive-frictional Materials 5(6):443-467

VanDine DF, Bovis M (2002) History and goals of Canadian debris flow research, a review. Nat Hazards 26(1):67-80

Wang FW, Sassa K (2010) Landslide simulation by a geotechnical mode combined with a model for apparent friction change. Phys Chem Earth 35:149-161

Zoppou C, Roberts S (2000) Numerical solution of the two-dimensional unsteady dam break. Appl Math Model 24(7):457-475

\section{Submit your manuscript to a SpringerOpen ${ }^{\circ}$ journal and benefit from:}

- Convenient online submission

- Rigorous peer review

- Immediate publication on acceptance

- Open access: articles freely available online

- High visibility within the field

- Retaining the copyright to your article

Submit your next manuscript at $\gg$ springeropen.com 